American Journal of Applied Sciences 9 (2): 250-253, 2012

ISSN 1546-9239

(C) 2012 Science Publications

\title{
Study on Optical Constants and Refractive Index Dispersion of Neutral red Doped Polymer Film
}

\author{
Hussain A. Badran \\ Department of Physics, College of Education, University of Basrah, Basrah, Iraq
}

\begin{abstract}
Problem statement: The some optical constants polymer thin film with red dye 3-amino-7dimethylamino-2-methyl phenazine (NR) as the guest material and Polyvinylpyrrolidone (PVP) as the host material were prepared by adulteration and spin-coating methods. Approach: The values of some important parameters (refractive index $\mathrm{n}$, extinction coefficient $\mathrm{K}$ and dielectric constant $\varepsilon_{\infty}$ ) of polymer thin film are determined from these spectra. Results: It has been found that the dispersion data obey the single oscillator relation of the Wemple-DiDomenico model, from which the dispersion parameters and high-frequency dielectric constant were determined. The estimation of the $\mathrm{E}_{0}, \mathrm{E}_{\mathrm{d}}$ and $\varepsilon_{\infty}$ are 1.27, 3.175 and $3.5 \mathrm{eV}$ respectively. Conclusion: The single oscillator model was used to calculate their optical constants from the transmittance and reflectance spectra. The dispersion of the refractive index in film follow the single electronic oscillator mode relation. The UV-Visible spectroscopic studies showed that, the NR film have high refractive index and high dielectric constant. The variation of the dielectric constant with the wavelength indicates that some interactions between photon and electrons in the films are produced in this wavelength range. These interactions are observed on the shapes of the real and imaginary parts of the dielectric constant and they cause the formation of peaks in the dielectric spectra which depends on the material type.
\end{abstract}

Key words: Optical properties, Thin film, azo dye, Polyvinylpyrrolidone (PVP), Neutral Red (NR), phenazine doped, extinction coefficient, dielectric constant, polymer thin film, dispersion parameters

\section{INTRODUCTION}

The process of thin film deposition involves the deposition of material atom-by-atom, molecule-bymolecule, ion-by-ion or cluster of species by cluster of species condensation (Preoneanu et al., 1995; Koksbang et al., 1994). This methodology is applied extensively in the manufacture of photocells and is being used in optical coating, microelectronics, surface science engineering and other technologies (Krunks and Mellikov, 1995; Susilawati and Doyan, 2009; Supa'at et al., 2008).

The investigation of the optical constants such as refractive index, extinction coefficient and dielectric constant of the 3- amino-7-dimethylamino-2-methyl phenazine doped polymer film are important for designing of new materials. Optical constants include the valuable information for technological applications. Furthermore, the changes in refractive index are important for controlling optical properties of thin polymer. Optical properties of any organic thin films are important for optical applications, because optical properties are directly related to their structural and electronic properties. The main aim of this study is to investigate the optical properties of polymer thin film with 3- amino-7-dimethylamino-2-methyl phenazine using the optical spectra.

\section{MATERIALS AND METHODS}

The molecular structure of 3- amino-7dimethylamino-2-methyl phenazine (Neutral Red) is shown in Fig. 1. In our experiment, the host material is Polyvinylpyrrolidone (PVP) and the ratio of Neutral Red in PVP by weight is $0.6 \%$. The NR-doped PVP films were prepared as follows: Neutral Red and PVP are dissolved separately in distilled water and then the solution of Neutral Red (NR) and that of PVP are mixed, heated (up to $50^{\circ} \mathrm{C}$ ) and stirred for $2 \mathrm{~h}$; thus the mixed sols of NR and PVP were obtained. After the sols were filtrated, the films were prepared on a clean glass slide by the repeat-spin-coating method and dried at room temperature for $48 \mathrm{~h}$. The thickness of the film is about $0.7 \mu \mathrm{m}$ and the film samples have good purity and uniform thickens.

The absorption spectrum of the film sample is shown in Fig. 2, where the peak of absorption is located at $533 \mathrm{~nm}$. In addition, our experimental results show that 3- amino-7-dimethylamino-2-methyl phenazine doped. Polymers have a stronger photo-induced birefringence effect (El-Nahass et al., 2010). 
<smiles></smiles>

Fig. 1: Molecular structure of neutral red dye molecule

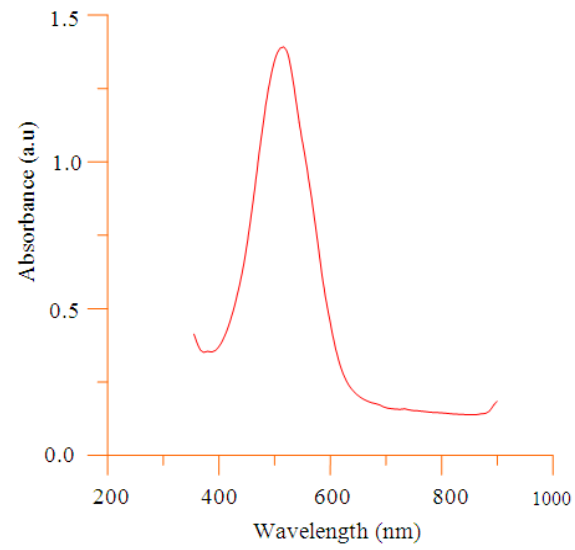

Fig. 2: Absorption spectra of neutral red-doped thin film

\section{RESULTS AND DISCUSSION}

\section{Dielectric constant:}

Refractive index dispersion :Figure $3 \mathrm{a}$ and $\mathrm{b}$ show the transmittance and reflectance spectra of the 3- amino-7dimethylamino-2-methyl phenazine. As seen in figures, the direct electronic transitions from $\pi$ to $\pi^{*}$ orbital's in the $300-450 \mathrm{~nm}$ range results in an intense band called the Soret band, which gives the absorption edge in 3amino-7-dimethylamino-2-methyl phenazine (Unni and Menon, 2000). The other band of the NR is the Q-band, which appears in the region between 550 and $750 \mathrm{~nm}$.

The reflectance spectrum was used to calculate the refractive index of the NR. The refractive index can be determined from the following Eq. 1 relation (Farag and Yahia, 2010):

$\mathrm{R}=\frac{(\mathrm{n}-1)^{2}+\mathrm{k}^{2}}{(\mathrm{n}+1)^{2}+\mathrm{k}^{2}}$

where, $\mathrm{k}$ is the extinction coefficient and was calculated using $\mathrm{k}=\alpha \lambda / 4 \pi$. Figure $4 \mathrm{a}$ and $\mathrm{b}$ show the real and imaginary parts of the refractive index of the NR .It is seen that the refractive index $\mathrm{n}$ changes with the wavelength and shows peak. In the region between 550 and $750 \mathrm{~nm}$ a $\mathrm{Q}$ band was observed.

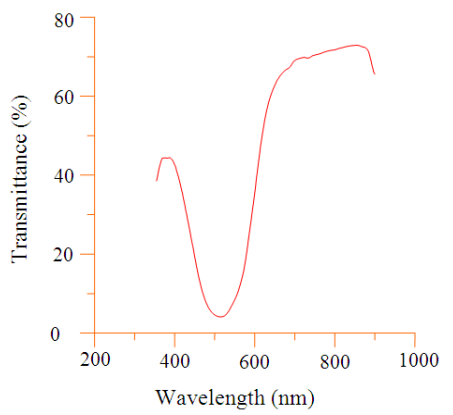

(a)

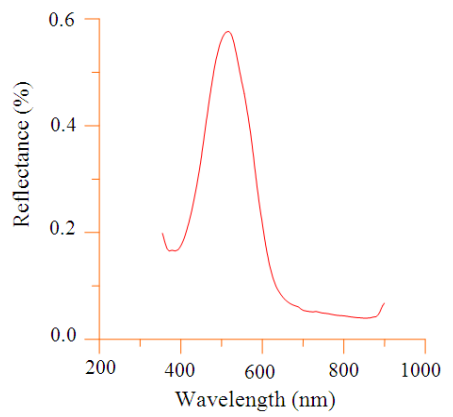

(b)

Fig. 3:The transmittance and reflectance spectra of the sample

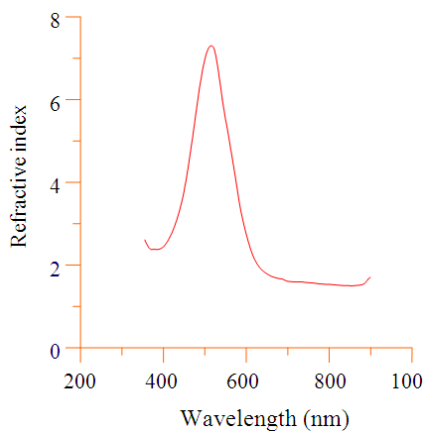

(a)

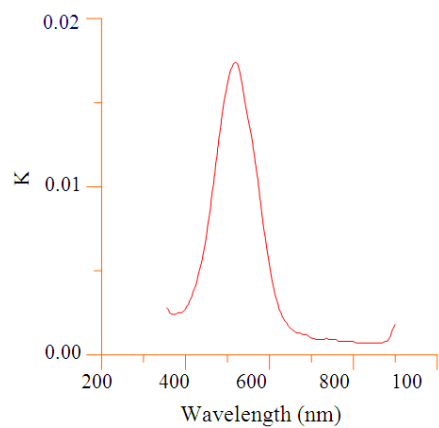

(b)

Fig. 4: The real and imaginary parts of refractive index with wavelength 
Am. J. Applied Sci., 9 (2): 250-253, 2012

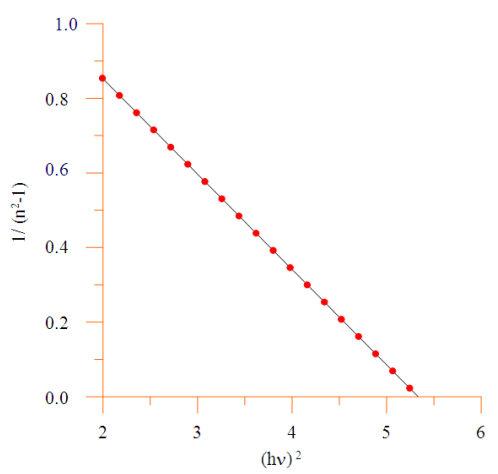

Fig. 5: plot of 1/ $\left(n^{2}-1\right)$ Vs $(h v)^{2}$

Table 1: The optical parameters of the film

\begin{tabular}{llllllll}
\hline Sample & $\mathrm{E}_{0}(\mathrm{eV})$ & $\mathrm{E}_{\mathrm{d}}(\mathrm{eV})$ & $\varepsilon_{\infty}$ & $\mathrm{n}(0)$ & $\mathrm{S}_{0}\left(\mathrm{~m}^{-2}\right)$ & $\mathrm{M}_{-1}$ & $\mathrm{M}_{-3}(\mathrm{eV})^{-2}$ \\
\hline $\begin{array}{l}\text { Neutral } \\
\text { red }\end{array}$ & 1.27 & 3.175 & 3.5 & 1.87 & $2.14 \times 10^{13}$ & 2.5 & 1.55 \\
\hline
\end{tabular}

There is little variation in the position of peaks and the magnitude of the peaks is greater. A normal dispersion was observed at $\lambda<500 \mathrm{~nm}$ as well as anomalous dispersion at, $\lambda>500 \mathrm{~nm}$.

Based on the single-oscillator model (Wemple and Didomenico, 1971) is a semi-empirical dispertion relation for determining the refractive index $\mathrm{n}$ at photon energy h $v$ can be written as follows Eq. 2:

$$
\mathrm{n}^{2}=1+\frac{\mathrm{E}_{\mathrm{d}} \mathrm{E}_{0}}{\mathrm{E}_{0}^{2}-(\mathrm{hv})^{2}}
$$

Where:

$\mathrm{h}=$ The Planck constant

$v=$ The frequency

$\mathrm{E}_{\mathrm{o}}=$ the average excitation energy for electronic transitions

$E_{d}=$ The dispersion energy which is measure of the average strength of inter-band optical transitions or the oscillator strength

By plotting $\left(\mathrm{n}^{2}-1\right)^{-1}$ against $(\mathrm{hv})^{2}$ and fitting a straight line as shown in Fig. $5\left(\mathrm{E}_{0} \mathrm{E}_{\mathrm{d}}\right)^{-1}$ and the intercept $\left(\mathrm{E}_{0} / \mathrm{E}_{\mathrm{d}}\right)$, on the vertical axis.

The long wavelength refractive index $\left(\mathrm{n}_{\infty}\right)$ and average oscillator wavelength $\left(\lambda_{0}\right)$ and oscillator length strength $S_{o}$ parameters for the NR can be determined by the single oscillator model given by Eq. 3 (Abdelmoneim, 2010):

$$
\frac{\left(\mathrm{n}_{\infty}^{2}-1\right)}{\left(\mathrm{n}^{2}-1\right)}=1-\left(\frac{\lambda_{\mathrm{o}}}{\lambda}\right)^{2}
$$

$\mathrm{n}_{\infty}$ value for the polymers film was obtained from the linear parts of $1 /\left(n^{2}-1\right)$ Vs $\lambda^{-2}$ curves plotted and is given in Table 1. Rearranging of Eq. 1-4 gives:

$$
\mathrm{n}^{2}-1=\frac{\mathrm{S}_{0} \lambda_{0}^{2}}{\left(1-\lambda_{0}^{2}\right) / \lambda^{2}}
$$

where, $\mathrm{S}_{0}=\left(\mathrm{n}_{\infty}^{2}-1\right) / \lambda_{0}^{2}$ is the average oscillator parameter which is the strength of the individual dipole oscillator. The $S_{0}$ values for the NR is calculated using Eq. 4 and are given in Table 1.

The $\mathrm{M}_{-1}$ and $\mathrm{M}_{-3}$ moments of the optical spectra can be obtained from the relationship Eq. 5 (Yakuphanoglu et al., 2004):

$E_{0}^{2}=\frac{M_{-1}}{M_{-3}}, E_{d}^{2}=\frac{M_{-1}^{3}}{M_{-3}}$

The $\mathrm{M}_{-1}$ and $\mathrm{M}_{-3}$ moments were calculated using equation 5 and are given in Table 1 . The $\mathrm{M}_{-1}$ and $\mathrm{M}_{-3}$ moments changed due to the formation coordination of complex.

It is found that $M_{-1}$ values decrease with atomic number of metal ion in the compounds. Whereas $\mathrm{M}_{-3}$ moments do not indicate any certain trend.

Dielectric constant:Once the dielectric function is known, it may be used to study the optical properties of the material studied. The dielectric constant can be defined as $\varepsilon(\omega)=\varepsilon_{1}(\omega)+\mathrm{i} \varepsilon_{2}(\omega)$ and real and imaginary parts of the dielectric constant are related to $\mathrm{n}$ and $\mathrm{k}$ values and these values were calculated using the formulas Eq. 6 (El-Korashy et al., 2003; Wakkad et al., 2000):

$\varepsilon_{1}(\omega)=\mathrm{n}^{2}(\omega)-\mathrm{k}^{2}(\omega), \varepsilon_{2}(\omega)=2 \mathrm{n}(\omega) \mathrm{k}(\omega)$

The $\varepsilon_{1}$ and $\varepsilon_{2}$ values for the film were calculated using Eq.(6) and are shown in Fig. 6a and b. The real part of the dielectric constant of the 3- amino-7dimethylamino-2-methyl phenazine (NR) is higher than that of the imaginary part.

The real part of the dielectric constant relates to dispersion, whereas dissipative rate of the electromagnetic wave in the dielectric medium is provided by imaginary part. The UV-visible spectra of 3- amino-7-dimethylamino-2-methyl phenazine (NR) show some intense bands which are at ranges of 250450 and $550-800 \mathrm{~nm}$. The intensity and position of peaks observed change by metal coordination. 
Am. J. Applied Sci., 9 (2): 250-253, 2012

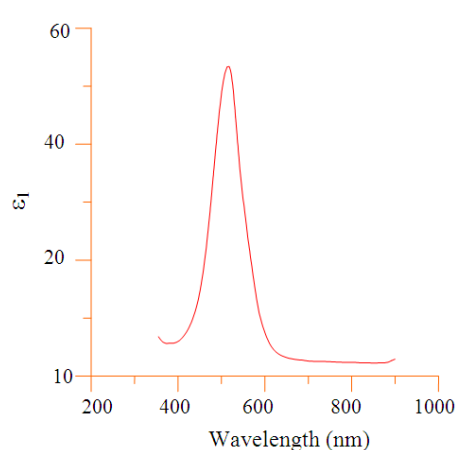

(a)

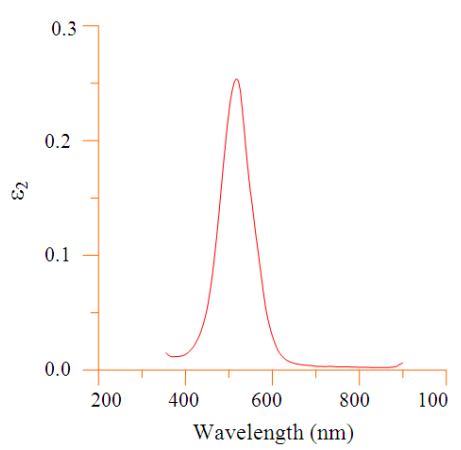

(b)

Fig. 6: The real and imaginary parts of the dielectric constant with wavelength

\section{CONCLUSION}

Optical properties of the dye polymer film by 3amino-7-dimethylamino-2-methyl phenazine (NR) doped in Polyvinylpyrrolidone PVP have been investigated to obtain the optical constants. The refractive index dispersion parameters, oscillator energy $E_{0}$, dispersion energy $E_{a}$, long wavelength refractive index $\mathrm{n}_{\square}$ and oscillator length strength $\mathrm{S}_{0}$ change by metal coordination The optical moments $\mathrm{M}_{-1}$ and $\mathrm{M}_{-3}$ of NR were calculated. The real and imaginary parts of the thin film were calculated.

\section{REFERENCES}

Abdelmoneim, H.M., 2010. Optical properties of $\mathrm{Ti}_{0.5} \mathrm{Li}_{0.5} \mathrm{La}_{0.1} \mathrm{Fe}_{1.9} \mathrm{O}_{4}$ ferrite thin film. Phys. B: Condensed Matt., 405: 1551-1557. DOI: 10.1016/j.physb.2009.12.038

El-Korashy, A., H. El-Zahed and M. Radwan, 2003. Optical studies of $\left[\mathrm{N}\left(\mathrm{CH}_{3}\right)_{4}\right]_{2} \mathrm{CoCl}_{4}$, $\left[\mathrm{N}\left(\mathrm{CH}_{3}\right)_{4}\right]_{2} \mathrm{MnCl}_{4}$ single crystals in the normal paraelectric phase. Phys. B: Condensed Matt., 334: 75-81. DOI: 10.1016/S0921-4526(03)00019-X
El-Nahass, M.M., A.F. El-Deeb, H.S. Metwally and A.M. Hassanien, 2010. Structural and optical properties of iron (III) chloride tetraphenylporphyrin thin films. Eur. Phys. J. Applied Phys., 52: 10403-10411. DOI: 10.1051/epjap/2010134

Farag, A.A.M. and I.S. Yahia, 2010. Structural, absorption and optical dispersion characteristics of rhodamine B thin films prepared by drop casting technique. Optics Commun., 283: 4310-4317. DOI: 10.1016/j.optcom.2010.06.081

Koksbang, R., I.I. Olsen and D. Shackle, 1994. Review of hybrid polymer electrolytes and rechargeable lithium batteries. Solid State Ionics, 69: 320-335. DOI: 10.1016/0167-2738(94)90420-0

Krunks, M. and E. Mellikov, 1995. Zinc oxide thin films by the spray pyrolysis method. Thin Solid Films, 270: 33-36. DOI: 10.1016/00406090(95)06893-7

Preoneanu, S., R. Torcu, M. Brie and G. Mihilesan, 1995. Electrochemical and optical studies of metallic ion insertion in polypyrrole film. Mater. Sci. Forum, 191: 241-246 DOI: 10.4028/www.scientific.net/MSF.191.241

Supa'at, A.S.M., M.H. Ibrahim, A.B. Mohammad, N.M. Kassim and N.E. Ghazali, 2008. A novel thermooptic polymer switch based on directional coupler structure. Am. J. Applied Sci., 5: 15521557. DOI: 10.3844/ajassp.2008.1552.1557

Susilawati and A. Doyan, 2009. Dose response and optical properties of dyed poly vinyl alcoholtrichloroacetic acid polymeric blends irradiated with gamma-rays. Am. J. Applied Sci., 6: 20712077. DOI: 10.3844/ajassp.2009.2071.2077

Unni, K.N.N. and C.S. Menon, 2000. Electrical, optical and structural studies on nickel phthalocyanine thin films. Mater. Lett., 45: 326-330. DOI: 10.1016/S0167-577X(00)00127-0

Wakkad, M.M., E.K. Shokr and S.H. Mohamed, 2000 Optical and calorimetric studies of $\mathrm{Ge}-\mathrm{Sb}-\mathrm{Se}$ glasses. J. Non-Cryst. Solids, 265: 157-166. DOI: 10.1016/S0022-3093(99)00882-0

Wemple, S.H. and M. Didomenico, Jr., 1971. Behavior of the Electronic Dielectric Constant in Covalent and Ionic Materials. Phys. Rev., B3: 1338-13511351. DOI: 10.1103/PhysRevB.3.1338

Yakuphanoglu, F., A. Cukurovali and I. Yilmaz, 2004. Determination and analysis of the dispersive optical constants of some organic thin films. Phys. B: Condensed Matt., 351: 53-58. DOI: 10.1016/j.physb.2004.05.010 